\title{
Development of Selective Media for Komagataeibacter intermedius and Dekkera bruxellensis from a Mixed Culture
}

\author{
Ferren Pratama, Putu Virgina Partha Devanthi, Katherine Kho* \\ Department of Biotechnology, School of Life Sciences, Indonesia International Institute for Life Sci-
} ences

*Corresponding author:

E-mail: katherine.k@i3l.ac.id

\begin{abstract}
Komagataeibacter intermedius and Dekkera bruxellensis are some of the most commonly found bacteria and yeast, respectively, during Kombucha fermentation. The development of selective media for separating both species is essential to make an accurate cell enumeration. This study aimed to develop a selective media for the enumeration of $K$. intermedius and $D$. bruxellensis from a mixed culture sample. Hestrin and Schramm (HS) agar and Potato Dextrose Agar (PDA) were chosen as the enumeration media for K. intermedius and D. bruxellensis, respectively. To select for $K$. intermedius, HS agar was added with various concentrations of cycloheximide $(0,1$, and $10 \mathrm{mg} / \mathrm{mL}), \mathrm{NaCl}(2 \%$ and $5 \%)$, and acetic acid $(1 \%)$. To select for $D$. bruxellensis, PDA was added with various concentrations of chloramphenicol $(0,0.3$, and $3 \mu \mathrm{g} / \mathrm{mL})$ and $\mathrm{NaCl}(2 \%$ and $5 \%)$. Each culture $\left(\sim 10^{6} \log \mathrm{CFU} / \mathrm{mL}\right)$ was serially diluted and plated on the respective agar media, followed by incubation at $30^{\circ} \mathrm{C}$ for 1-6 days. The results showed that PDA containing $2 \% \mathrm{NaCl}$ could completely suppress $K$. intermedius growth while permitting complete recovery of D. bruxellensis. However, it took 6 days until visible growth was observed by $D$. bruxellensis. Moreover, HS with the addition of $1 \%$ acetic acid successfully inhibited D.bruxellensis while allowing the complete recovery of $K$. intermedius. The findings suggested that the two media were suitable for separating $K$. intermedius and $D$. bruxellensis on agar media, thus allowing a more accurate cell counting in studies involving the mixed cultures of both species.
\end{abstract}

Keywords: Selective media, Dekkera bruxellensis, Komagataeibacter intermedius

\section{Introduction}

Kombucha is a sugar tea drink fermented by a symbiotic culture of bacteria and yeasts (SCOBY). These symbionts act in concert during the fermentation, converting sugars into a range of secondary metabolites and bioactive compounds with potential health benefits (Chakravorty et al., 2016). The fermentation also results in the production of bacterial cellulose, which finds applications in various industries, including textile, food, medical, and pharmaceutical industries (Azeredo et al., 2019; Ul-Islam et al., 2020). Since bacteria and yeast play a vital role in the formation of these by-products, studies focusing on the interaction between them during fermentation are paramount.

Previously, Angela et al. (2020) have isolated bacteria and yeast predominant during Kombucha fermentation, identified as Komagataeibacter intermedius and Dekkera bruxellensis, respectively. The high bacterial cellulose-producing capacity of $K$. intermedius has been reported in several studies (Angela et al., 2020; Fernández et al., 2019; Lin et al., 2016). Unlike Acetobacter xylinum, the most commonly used bacterial cellulose producer, $K$. intermedius is able to produce bacterial cellulose within a wide $\mathrm{pH}$ range ( $\mathrm{pH}$ 4-9) (Lin et al., 2016). A mixed culture of $K$. intermedius and D. bruxellensis was also shown to increase the production of glucuronic acid by $\sim 184 \%$ compared to the use of $K$. intermedius alone (Nguyen et al., 2015). Understanding the dynamics of both microbes resulting from their interactions could allow better control of fermentation (May et al., 2019).

One way of observing the microbes' dynamics during fermentation is by measuring their viable cell count. However, as K. intermedius and D. bruxellensis colonies' morphology look nearly identical, cell counting results would be unreliable when they are grown at the same time. Therefore, for the study,

\section{How to cite:}

Pratama. F., Devanthi, P. V; P., \& Kho, K. (2021). Development of selective media for Komagataeibacter intermedius and Dekkera bruxellensis fro a mixed culture. Basic and Applied Science Conference (BASC) 2021. NST Proceedings. pages 3238. doi: 10.11594/ nstp.2021.1106 
both cultures need to be grown on selective media. A common strategy for allowing selective growth in microbes would be to use antibiotics. An antifungal agent when bacterial growth is desired and an antibacterial agent when fungal growth is desired (Bonnet et al., 2020). Cycloheximide is an example of an antifungal agent usually used to suppress eukaryotic growth and more importantly, fungi from mixed cultures (Chauhan \& Jindal, 2020). While chloramphenicol is a common antimicrobial agent due to being effective towards a wide spectrum of bacteria (Anderson et al., 2012).

Besides antibiotics, potentially effective alternatives were also considered that were less expensive and safer to handle. $K$. intermedius is known for its high tolerance to acetic acid (Andrés-Barrao et al., 2016), while several yeast strains are known for their susceptibility to certain concentrations of acetic acid (Moktaduzzaman et al., 2016). This information suggests a possibility to use acetic acid to select for $K$. intermedius from its co-culture with $D$. bruxellensis. $\mathrm{NaCl}$ is another potential selective agent that can be used. $D$. bruxellensis is known for its ability to survive osmotic stress induced by salt at low concentrations, including $\mathrm{NaCl}$ (Zemančíková et al., 2018). Meanwhile, to date, there is no study reporting Komagataeibacter tolerance for $\mathrm{NaCl}$-induced osmotic stress. In this study, acetic acid and $\mathrm{NaCl}$ of varying concentrations were added into the isolation media, and their effectiveness in separating $K$. intermedius and D. bruxellensis was evaluated.

\section{Material and Methods \\ Culture and media preparation}

$K$. intermedius and D. bruxellensis were previously isolated by Angela et al. (2020) from kombucha tea provided by PT. Tujju Kombucha (Jakarta, Indonesia). K. intermedius was maintained on Hestrin Schramm (HS) agar at $4^{\circ} \mathrm{C}$, while D. bruxellensis was maintained on Potato Dextrose Agar (PDA) at $4^{\circ} \mathrm{C}$. HS broth and Potato Dextrose Broth (PDB) were prepared to culture the microbes for the selective media test. HS media consisted of $20 \mathrm{~g} / \mathrm{L}$ glucose, $5 \mathrm{~g} / \mathrm{L}$ peptone, $5 \mathrm{~g} / \mathrm{L}$ yeast extract, $2.7 \mathrm{~g} / \mathrm{L} \mathrm{Na} \mathrm{HPO}_{4}$ and $1.15 \mathrm{~g} / \mathrm{L}$ citric acid. $\mathrm{NaCl}$ was directly added into the agar before being autoclaved; acetic acid and antibiotics were added to the agar after autoclave following filter sterilization using $0.22 \mu \mathrm{m}$ membrane.

\section{Evaluation of selective agents on the enumeration of tested strains}

First, $K$. intermedius and D. bruxellensis were cultured in HS broth and PDB, respectively, at $30^{\circ} \mathrm{C}$ for 24 hours. Both broth cultures were then diluted serially using a $0.85 \% \mathrm{NaCl}(\mathrm{w} / \mathrm{v})$ solution and plated on the selective agar using the Miles and Misra method (Miles et al., 1938). To select for K. intermedius, HS agar was added with either cycloheximide $(1 \mathrm{mg} / \mathrm{mL}$ and $10 \mathrm{mg} / \mathrm{mL})$ or $1 \%(\mathrm{v} / \mathrm{v})$ acetic acid. Then, to select for D. bruxellensis, PDA was added with either chloramphenicol $(0.3 \mu \mathrm{g} / \mathrm{mL}$ and $3 \mu \mathrm{g} / \mathrm{mL})$ or $\mathrm{NaCl}(2 \%$ and $5 \% \mathrm{w} / \mathrm{v})$. As a negative control, $K$. intermedius and D. bruxellensis were also grown on HS agar and PDA, respectively, in the absence of selective agents. The plates were then incubated at $30^{\circ} \mathrm{C}$. The CFU of both microbes were observed after 48 and 144 hours of incubation.

\section{Results and Discussion}

In this study, selective agents to separate $K$. intermedius and $D$. bruxellensis from a mixed culture during plate counting were explored. The results are reported in Table 1 and Table 2, respectively. Both microbes were found to be unaffected by antibiotics but fully inhibited by $5 \% \mathrm{NaCl}$.

As shown in Table 1, the CFU count of yeast grown in HS media with cycloheximide was not significantly different ( $p>0.05$ ) from the CFU count of the yeast grown in HS media without cycloheximide at $3 \pm 0.4 \times 10^{6} \mathrm{CFU} / \mathrm{mL}$ (Table 1). Although the exact mechanism is still unclear, cycloheximide inhibits cytosolic protein synthesis by binding to the large 80 s ribosome subunit (Stevens et al., 2001). According to Ciani and Comitini (2014), D. bruxellensis is able to tolerate concentrations up to $1 \mathrm{mg} / \mathrm{mL}$ of cycloheximide in some cases. Moreover, multiple studies have confirmed the resistance of $D$. bruxellensis towards cycloheximide (Steensels et al., 2015; Morneau et al., 2011). A further increase in cycloheximide concentration to $10 \mathrm{mg} / \mathrm{mL}$ confirmed the inability of cycloheximide to inhibit $D$. bruxellensis growth. It is also noted that this concentration is 100 times higher than the working concentration. 
The exact mechanism of resistance in $D$. bruxellensis is also still unknown, but some studies have found several ways other fungi resist cycloheximide which D. bruxellensis may utilise. In Candida albicans, the expression of two certain $\mathrm{ABC}$ transporters ( $\mathrm{Cdr} 1$ and $\mathrm{Cdr} 2)$ are largely responsible for resistance towards different azole antibiotics, including cycloheximide (Ali et al., 2015). Additionally, the deletion of Cdr1, Cdr2, and other homologues have been found to result in sensitivity towards the azole antibiotics in yeasts (Sanglard et al., 2009). Another method of resistance was observed in Chlamydomonas reinhardtii by the replacement of a proline residue with glutamate in the L41 protein of the $80 \mathrm{~s}$ ribosomal subunit (Stevens et al., 2001; Ali et al., 2015). Besides that, D. bruxellensis is known for having more phenotypic diversity which may allow it to adapt to harmful environments (Avramova et al., 2018). Consequently, due to this resistance, other alternatives are usually recommended to suppress D. bruxellensis' growth in different kinds of industries, such as winemaking and ethanol production (Zuehlke et al., 2013; Beckner et al., 2011). Continuing to use antifungals to suppress D. bruxellensis may be ineffective as another study by Rodrigues et al. (2001) found that different strains may be resistant to other antifungals as well.

Compared to the negative control, $D$. bruxellensis needed 6 days to grow in $2 \% \mathrm{NaCl}$ before the colonies were visible enough to count. Nonetheless, D. bruxellensis was found to be able to grow in the presence of $2 \% \mathrm{NaCl}$ with a CFU count of $1.24 \pm 0.2 \times 10^{6} \mathrm{CFU} / \mathrm{mL}$. D. bruxellensis is known for being able to tolerate up to $3.38 \%$ of $\mathrm{NaCl}$ (Stratford et al., 2019). The sulphite tolerance gene (SSU1) and the HOG-kinase pathway, found in most other fungal species, seem to be responsible for D. bruxellensis ' slight osmotolerance (Curtin et al., 2014). However, compared to other yeasts, D. bruxellensis is considered to be sensitive towards $\mathrm{NaCl}$ which explains why a longer incubation period was required (Bubnová et al., 2014; Zemančíková et al. 2018). On the other hand, 1\% acetic acid was found to fully inhibit the growth of $D$. bruxellensis with no growth observed even after 6 days of incubation. Although $D$. bruxellensis is an acetic acid producer, it could only produce a maximum of $0.3 \%$ acetic acid (Freer, 2002). Furthermore, D. bruxellensis is susceptible to around $0.6 \%$ to $0.8 \%$ acetic acid (Uscanga et al., 2000). The presence of acetic acid not only inhibits D. bruxellensis' glucose uptake, but also causes oxidative stress in the cells and can disrupt its internal pH (Moktaduzzaman et al., 2015).

Table 1. The effect of a selective agent towards yeast growth

\begin{tabular}{|c|c|c|c|c|}
\hline Media & Selective agent & $\begin{array}{c}\text { The concentration of selec- } \\
\text { tive agent }\end{array}$ & $\begin{array}{l}\text { The incubation pe- } \\
\text { riod (days) }\end{array}$ & $\begin{array}{l}\text { Yeast count } \\
(\mathrm{CFU} / \mathrm{ml})\end{array}$ \\
\hline \multirow{6}{*}{ HS } & \multirow{3}{*}{ Cycloheximide } & $0 * *$ & 2 & $3.5 \pm 0.3 \times 10^{6}$ \\
\hline & & $1 \mathrm{mg} / \mathrm{ml}$ & 2 & $3.9 \pm 0.5 \times 10^{6}$ \\
\hline & & $10 \mathrm{mg} / \mathrm{ml}$ & 2 & $3 \pm 0.4 \times 10^{6}$ \\
\hline & Acetic acid & $1 \%$ & 6 & No growth \\
\hline & \multirow{2}{*}{$\mathrm{NaCl}$} & $2 \%$ & 6 & TNTC \\
\hline & & $5 \%$ & 6 & No growth \\
\hline \multirow{2}{*}{ PDA } & \multirow{2}{*}{$\mathrm{NaCl}$} & $2 \%$ & 6 & $1.24 \pm 0.2 \times 10^{6}$ \\
\hline & & $5 \%$ & 6 & No growth \\
\hline
\end{tabular}

* Student's t-test was performed at $95 \%$ confidence interval to analyze the effect of cycloheximide at different concentration levels toward yeast count $* *$ negative control 


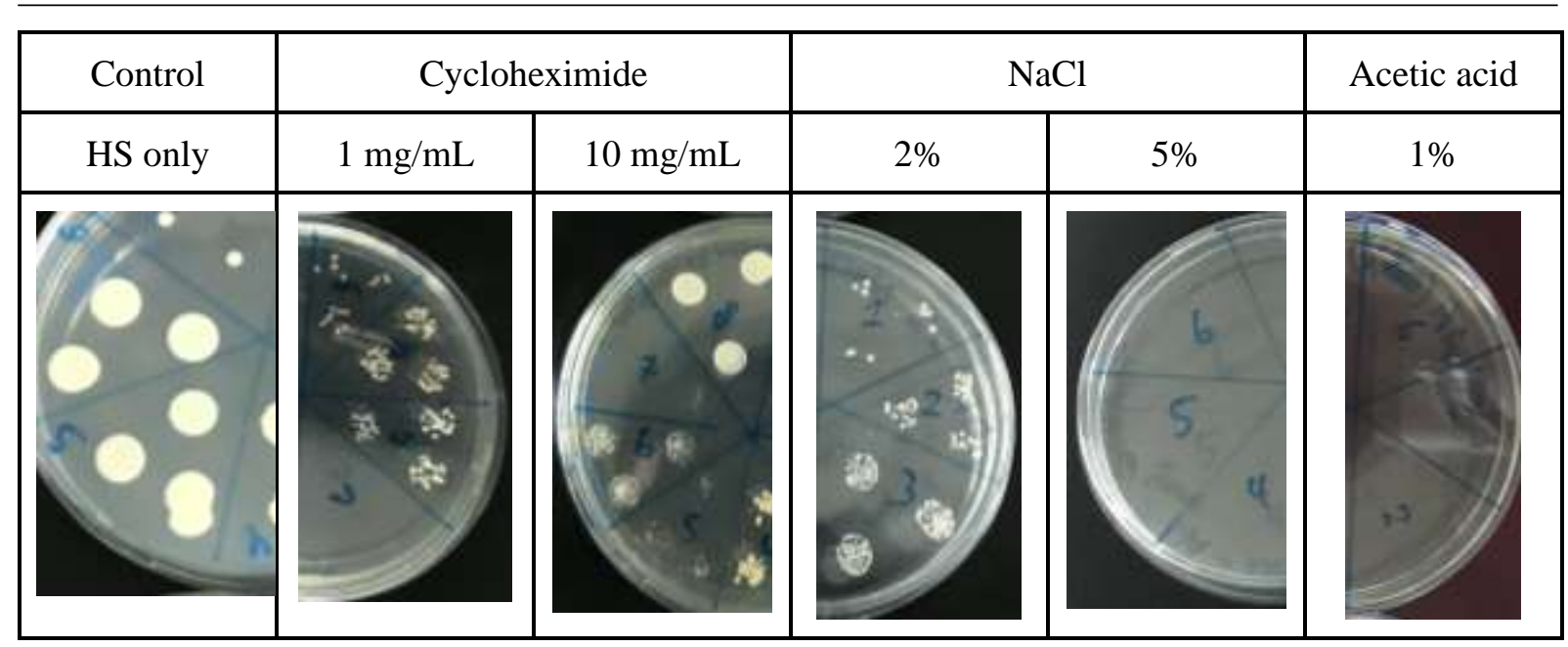

Figure 1. Growth of $D$. bruxellensis in the presence of different selective agents. Control and cycloheximide plates were observed after 2 days of incubation while $\mathrm{NaCl}$ and acetic acid plates were observed after 6 days of incubation.

As displayed in Table 2, the CFU count of the bacteria with or without chloramphenicol showed no significant difference $(\mathrm{p}>0.05)$. Chloramphenicol is a protein synthesis inhibitor which by reversibly binding to the 50s subunit of the 70s ribosome (Balbi, 2004). The concentration of chloramphenicol used in this study is considered to be effective towards Acetobacter which is in the same family as Komagataeibacter (Haghshenas et al., 2014). However, the current study showed that $K$. intermedius was able to grow unhindered in the presence of chloramphenicol as shown in Figure 1. A higher concentration may be required in order to suppress $K$. intermedius' growth as a previous study reported a higher concentration of $300 \mu \mathrm{g} / \mathrm{mL}$ and $100 \mu \mathrm{g} / \mathrm{mL}$ to be effective towards Komagataeibacter hansenii and Komagataeibacter xylinus respectively (Varley, 2017). Both concentrations are considered high and known resistant bacteria are also only affected by similar concentrations (Fernández et al., 2014). Another study also found that Komagataeibacter melaceti and Komagataeibacter melomenusus are resistant towards chloramphenicol as they possess a homologue for chloramphenicol acetyltransferase which inhibits the antibacterial activity (Marič et al., 2020).

As shown in figure 2, K. intermedius was found to be unable to grow in the both concentrations of $\mathrm{NaCl}$ even after 6 days of incubation. Komagataeibacter are known for being unable to tolerate more than $0.5 \% \mathrm{NaCl}$ (Prudnikova \& Shidlovsky, 2017). It is likely that the sodium ion affected the bacteria's plasma membrane properties and therefore the bacteria's viability (Gandhi et al., 2014). Meanwhile, $K$. intermedius was found to be able to grow in the presence of acetic acid at $1 \%$ with a countable CFU after only 2 days of incubation $\left(9.36 \pm 2.5 \times 10^{6} \mathrm{CFU} / \mathrm{mL}\right)$ (Figure 2). Komagataeibacter are able to produce up to $20 \%$ of acetic acid, indicating its high tolerance to acetic acid (Andrés-Barrao et al., 2016). Additionally, K. intermedius has also been found to tolerate around 6\% of acetic acid (Gomes et al., 2018). This resistance may be possible as it was found that an increase in concentration of acetic acid causes the Komagataeibacter to adapt using several strategies: an increase in cell surface area, an increase in efflux-pump systems, and modification of the protein and lipid membrane (Barja et al., 2016). 


\begin{tabular}{|c|c|c|c|c|}
\hline Media & Selective agent & $\begin{array}{c}\text { Concentration of selec- } \\
\text { tive agent }\end{array}$ & $\begin{array}{c}\text { Incubation period } \\
\text { (days) }\end{array}$ & $\begin{array}{l}\text { Yeast count } \\
(\mathrm{CFU} / \mathrm{ml})\end{array}$ \\
\hline \multirow{5}{*}{ PDA } & \multirow{3}{*}{ Chloramphenicol } & $0 * *$ & 2 & $8.53 \pm 1.6 \times 10^{6}$ \\
\hline & & $3 \mu \mathrm{g} / \mathrm{ml}$ & 2 & $4.6 \pm 0.5 \times 10^{7}$ \\
\hline & & $30 \mu \mathrm{g} / \mathrm{ml}$ & 2 & TNTC \\
\hline & \multirow{2}{*}{$\mathrm{NaCl}$} & $2 \%$ & 6 & No growth \\
\hline & & $5 \%$ & 6 & No growth \\
\hline \multirow{2}{*}{ HS } & \multirow{2}{*}{$\mathrm{NaCl}$} & $2 \%$ & 6 & No growth \\
\hline & & $5 \%$ & 6 & No growth \\
\hline & Acetic acid & $1 \%$ & 2 & $9.36 \pm 2.5 \times 10^{6}$ \\
\hline
\end{tabular}

*Student's t-test was performed at 95\% confidence interval to analyse the effect of chloramphenicol at different concentration levels toward bacteria count $* *$ negative control

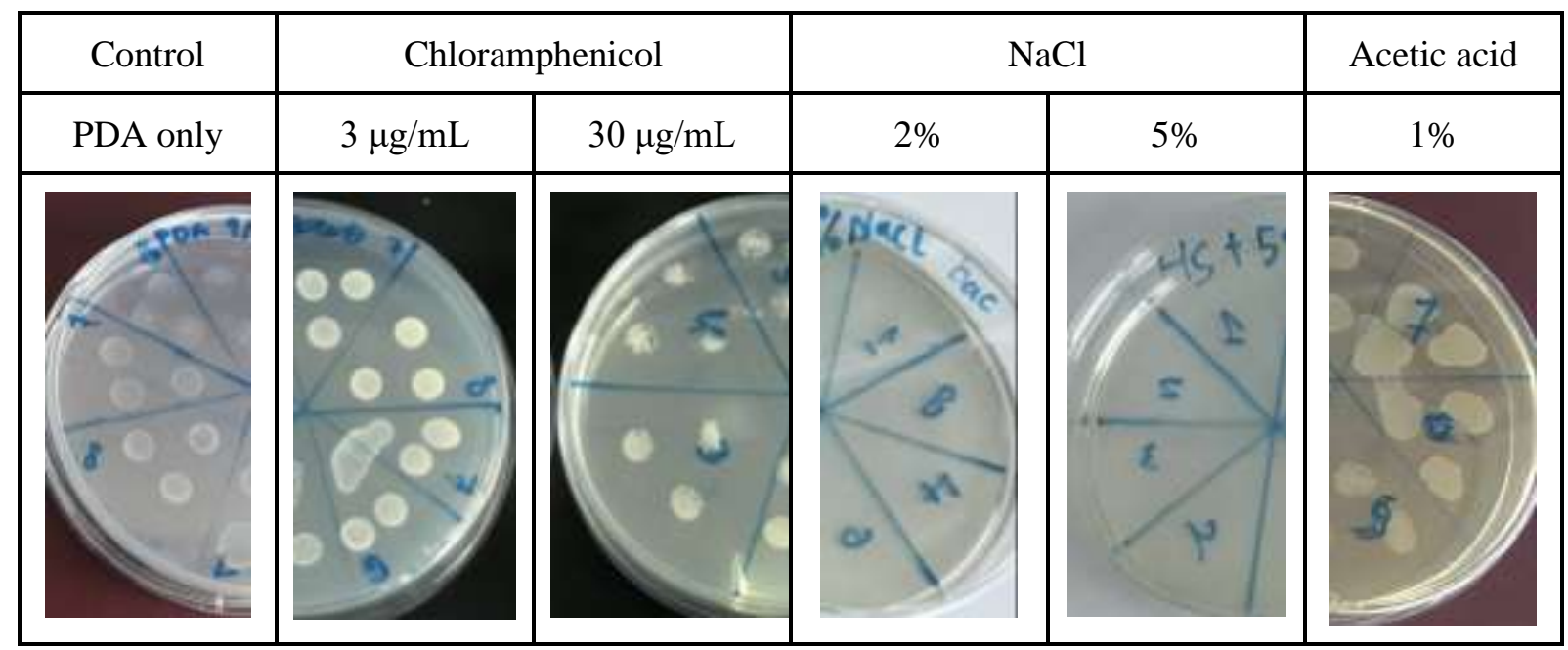

Figure 2. Growth of $K$. intermedius in the presence of different selective agents. Control, chloramphenicol and acetic acid plates were observed after 2 days of incubation. Plates containing $\mathrm{NaCl}$ were observed after 6 days of incubation.

\section{Conclusion}

In this study, we have developed selective media for Komagataeibacter intermedius and Dekkera bruxellensis from a mixed culture. Antibiotics at the concentrations tested were found ineffective towards the microbes tested in this study, suggesting either the need to use higher concentrations or alternatives. The results of this study showed that $\mathrm{NaCl} 2 \%$ can be used as a selective agent for D. bruxellensis from this mixed culture, albeit the slower growth. Furthermore, $1 \%$ acetic acid was found to be an effective selective agent for the bacteria as it was able to fully inhabit the growth of D. bruxellensis and did not hinder the growth of $K$. intermedius. 


\section{Acknowledgment}

The authors would like to thank Indonesia International Institute for Life Sciences for funding this research.

\section{References}

Ali, G. F., Al-Hamadani, A. H., \& Mohammad, A. W. (2015). Detection of Cycloheximide Resistant Gene in Selected Pathogenic Fungi. Journal of Contemporary Medical Sciences, 1(4), 23-26.

Anderson, A. J., Groundwater, P. W., Todd, A., \& Worsley, A.J. (2012). Chloramphenicol. Antibacterial Agents, $231-242$. doi:10.1002/9781118325421.ch10

Andrés-Barrao, C., Saad, M., Ferrete, E. C., Bravo, D., Chappuis, M., Pérez, R. O., Junier, P., Perret, X., \& Barja, F. (2016). Metaproteomics and ultrastructure characterization of Komagataeibacter spp. involved in high-acid spirit vinegar production. Food Microbiology, 55, 112-122. doi: 10.1016/j.fm.2015.10.012

Angela, C., Young, J., Kordayanti, S., Devanthi, P. V. P., \& Katherine. (2020). Isolation and Screening of Microbial Isolates from Kombucha Culture for Bacterial Cellulose Production in Sugarcane Molasses Medium. KnE Life Sciences, $2020,111-127$. https://doi.org/10.18502/kls.v5i2.6444

Avramova, M., Cibrario, A., Peltier, E., Coton, M., Coton, E., Schacherer, J., Spano, G., Capozzi, V., Blaiotta, G., Salin, F., Dols-Lafargue, M., Grbin, P., Curtin, C., Albertin, W., \& Masneuf-Pomarede, I. (2018). Brettanomyces bruxellensis Population Survey Reveals a Diploid-Triploid Complex Structured According to Substrate of Isolation and Geographical Distribution. Scientific Reports, 8, 4136. https://doi.org/10.1038/s41598-018-22580-7

Azeredo, H., Barud, H., Farinas, C., Vasconcellos, V., \& Claro, A. (2019). Bacterial Cellulose as a Raw Material for Food and Food Packaging Applications. Frontiers In Sustainable Food Systems, 3. doi: 10.3389/fsufs.2019.00007

Balbi, H. J. (2004). Chloramphenicol: A Review. Pediatrics in Review, 25(8), 284-288. doi:10.1542/pir.25-8-284

Barja, F., Barrao, C. A., Pérez, R. O., \& Cabello, E. M. (2016). Physiology of Komagataeibacter spp. during Acetic Acid Fermentation. Acetic Acid Bacteria, 201-221. 10.1007/978-4-431-55933-7 9

Beckner, M., Ivey, M. L., \& Phister, T. G. (2011). Microbial Contamination of Fuel Ethanol Fermentations. Applied Microbiology, 53(4), 1-5. https://doi.org/10.1111/j.1472-765X.2011.03124.X

Bonnet, M., Lagier, J., Raoult, D., \& Khelaifia, S. (2020). Bacterial culture through selective and non-selective conditions: the evolution of culture media in clinical microbiology. New Microbes and New Infections, 34, 100622. doi: 10.1016/j.nmni.2019.100622

Bubnová, M., Zemančíková, J., \& Sychrová, H. (2014). Osmotolerant Yeast Species Differ in Basic Physiological Parameters and in Tolerance of Non-osmotic Stresses. Yeast, 31(8), 309-321. doi:10.1002/yea.3024

Chakravorty, S., Bhattacharya, S., Chatzinotas, A., Chakraborty, W., Bhattacharya, D., \& Gachhui, R. (2016). Kombucha tea fermentation: Microbial and biochemical dynamics. International Journal of Food Microbiology, 220, 63-72. doi:10.1016/j.ijfoodmicro.2015.12.015

Chauhan, A., \& Jindal, T. (2020). Microbiological Culture Media: Types, Role and Composition. Microbiological Methods for Environment, Food and Pharmaceutical Analysis. (pp.23-66) Publisher: Springer, Cham. https://doi.org/10.1007/978-3-030-52024-3_3

Ciani, M., \& Comitini, F. (2014). Brettanomyces. Encyclopedia of Food Microbiology, 316-323. doi:10.1016/b978-0-12-384730-0.00046-X

Curtin, C. D., Pretorius IS Genomic Insights into the Evolution of Industrial Yeast Species Brettanomyces bruxellensis. FEMS Yeast Research, 14(7), 997-1005, https://doi.org/10.1111/1567-1364.12198

Fernández, J., Morena, A. G., Valenzuela, S. V., Pastor, F. I. J., Díaz, P., \& Martínez, J. (2019). Microbial Cellulose from a Komagataeibacter intermedius Strain Isolated from Commercial Wine Vinegar. Journal of Polymers and the Environment, 1(2), 1-5. doi:10.1007/s10924019-01403-4

Fernández, M., Conde, S., de la Torre, J., Molina-Santiago, C., Ramos, J. L., \& Duque, E. (2012). Mechanisms of resistance to chloramphenicol in Pseudomonas putida KT2440. Antimicrobial agents and chemotherapy, 56(2), 1001-1009. https://doi.org/10.1128/AAC.05398-11

Freer, S. N. (2002). Acetic Acid Production by Dekkera/Brettanomyces yeasts. World Journal of Microbiology and Biotechnology, 18(3), 271275. doi:10.1023/a:1014927129259

Gandhi, A., Cui, Y., Zhou, M., \& Shah, N. (2013). Effect of KCl substitution on bacterial viability of Escherichia coli (ATCC 25922) and selected probiotics. Journal of Dairy Science, 97(10). http://dx.doi.org/ 10.3168/jds.2013-7681

Gomes, R. J., Borges, M. F., Rosa, M. F., Castro-Gómez, R., \& Spinosa, W. A. (2018). Acetic Acid Bacteria in the Food Industry: Systematics, Characteristics and Applications. Food technology and biotechnology, 56(2), 139-151. https://doi.org/10.17113/ftb.56.02.18.5593

Haghshenas, B., Nami, Y., Abdullah, N., Radiah, D., Rosli, R., Barzegari, A, \& Yari Khosroushahi, A. (2014). Potentially probiotic acetic acid bacteria isolation and identification from traditional dairies microbiota. International Journal of Food Science \& Technology, 50(4), 1056-1064. doi:10.1111/ijfs.12718 
Lin, S. P., Huang, Y. H., Hsu, K. D., Lai, Y. J., Chen, Y. K., \& Cheng, K. C. (2016). Isolation and identification of cellulose-producing strain Komagataeibacter intermedius from fermented fruit juice. Carbohydrate Polymers, 151, 827-833. https://doi.org/10.1016/j.carbpol.2016.06.032

Marič, L., Cleenwerck, I., Accetto, T., Vandamme, P., Trček, J. (2020). Description of Komagataeibacter melaceti sp. nov. and Komagataeibacter melomenusus sp. nov. Isolated from Apple Cider Vinegar. Microorganisms, 8(8), 1178. https://doi.org/10.3390/microorganisms 8081178

May, A., Narayanan, S., Alcock, J., Varsani, A., Maley, C., \& Aktipis, A. (2019). Kombucha: a novel model system for cooperation and conflict in a complex multi-species microbial ecosystem. PeerJ, 7, e7565. https://doi.org/10.7717/peerj.7565

Miles, A. A., Misra, S. S., \& Irwin, J. O. (1938). The estimation of the bactericidal power of the blood. The Journal of hygiene, 38(6), 732749. https://doi.org/10.1017/s002217240001158x

Moktaduzzaman, M., Galafassi, S., Vigentini, I., Foschino, R., Corte, L., Cardinali, G., Piškur, J., \& Compagno, C. (2016). Strain-dependent tolerance to acetic acid in Dekkera bruxellensis. Annals of Microbiology, 66, 351-359. https://doi.org/10.1007/s13213-015-1115-0

Morneau A, Zuehlke J, Edwards C (2011) Comparison of media formulations used to selectively cultivate Dekkera/Brettanomyces. Letters In Applied Microbiology, 53(4), 460-465. doi: 10.1111/j.1472-765x.2011.03133.x

Nguyen, N. K., Nguyen, P. B., Nguyen, H. T., \& Le, P. H. (2015). Screening the optimal ratio of symbiosis between isolated yeast and acetic acid bacteria strain from traditional kombucha for high-level production of glucuronic acid. LWT - Food Science and Technology, 64, 1149-1155. https://doi.org/10.1016/j.lwt.2015.07.018

Prudnikova, S. V., \& Shidlovsky, I. P. (2017). The new strain of acetic acid bacteria Komagataeibacter xylinus B-12068 - producer of bacterial cellulose for biomedical applications. Journal of Siberian Federal University, 10(2), 246-254. DOI: 10.17516/1997-1389- 0017.

Rodrigues, N., Goncalves, G., Pereira-da-Silva, S., Malfeito-Ferreira, M., \& Loureiro, V. (2001). Development and Use of a New Medium to Detect Yeasts of the Genera Dekkera/Brettanomyces. Journal of Applied Microbiology, 90(4), 588-599. doi: 10.1046/j.13652672.2001.01275.x

Sanglard, D., Coste, A., \& Ferrari, S. (2009). Antifungal drug resistance mechanisms in fungal pathogens from the perspective of transcriptional gene regulation. FEMS Yeast Research, 9(7), 1029-1050. https://doi.org/10.1111/j.1567-1364.2009.00578.x

Steensels, J., Daenen, L., Malcorps, P., Derdelinckx, G., Verachtert, H., \& Verstrepen, K. (2015). Brettanomyces yeasts — From spoilage organisms to valuable contributors to industrial fermentations. International Journal of Food Microbiology, 206, 24-38. doi: 10.1016/j.ijfoodmicro.2015.04.005

Stevens, D. R., Atteia, A., Franzén, L-G., \& Purton, S. (2001). Cycloheximide resistance conferred by novel mutations in ribosomal protein L41 of Chlamydomonas reinhardtii. Molecular and General Genetics MGG, 264(6), 790-795. doi:10.1007/s004380000368

Stratford, M., Steels, H., Novodvorska, M., Archer, D. B., \& Avery, S. V. (2019). Extreme Osmotolerance and Halotolerance in Food-Relevant Yeasts and the Role of Glycerol-Dependent Cell Individuality. Frontiers in Microbiology, 9, 3238. https://doi.org/10.3389/fmicb.2018.03238

Ul-Islam, M., Ullah, M. W., Khan, S., Park, J. K. (2020). Production of bacterial cellulose from alternative cheap and waste resources: A step for cost reduction with positive environmental aspects. Korean Journal of Chemical Engineering, 37(6), 925-937. doi:10.1007/s11814020-0524-3

Uscanga, M. G. A., Delia, M-L., \& Strehaiano, P. (2000). Nutritional requirements of Brettanomyces bruxellensis: Growth and physiology in batch and chemostat cultures. Canadian Journal of Microbiology, 46(11), 1046-1050. doi:10.1139/w00-089

Varley, A. J. (2017). The transcription factor, FixK, plays a central role in carbon source metabolism and cellulose synthesis in Komagataeibacter species. Masters thesis. University of Ontario, Faculty of Science.

Zemančíková, J., Dušková, M., Elicharová, H., Papoušková, K., \& Sychrová, H. (2018). Osmotolerance of Dekkera bruxellensis and the role of two Stl glycerol-proton symporters. FEMS Microbiology Letters, 365(5). doi: 10.1093/femsle/fny020

Zuehlke, J. M., Petrova, B., \& Edwards, C. G. (2013). Advances in the Control of Wine Spoilage by Zygosaccharomyces and Dekkera/Brettanomyces. Annual Review of Food Science and Technology, 4(1), 57-78. doi:10.1146/annurev-food-030212-182533 